\title{
Agreement of reported vascular access on the medical evidence report and on medicare claims at hemodialysis initiation
}

\author{
Craig A Solid ${ }^{*}$, Allan J Collins ${ }^{1,2}$, James P Ebben', Shu-Cheng Chen ${ }^{1}$, Arman Faravardeh³, Robert N Foley ${ }^{1,2}$ \\ and Areef Ishani $i^{1,2,4}$
}

\begin{abstract}
Background: The choice of vascular access type is an important aspect of care for incident hemodialysis patients. However, data from the Centers for Medicare \& Medicaid Services (CMS) Medical Evidence Report (form CMS-2728) identifying the first access for incident patients have not previously been validated. Medicare began requiring that vascular access type be reported on claims in July 2010. We aimed to determine the agreement between the reported vascular access at initiation from form CMS-2728 and from Medicare claims.

Methods: This retrospective study used a cohort of 9777 patients who initiated dialysis in the latter half of 2010 and were eligible for Medicare at the start of renal replacement therapy to compare the vascular access type reported on form CMS-2728 with the type reported on Medicare outpatient dialysis claims for the same patients. For each patient, the reported access from each data source was compiled; the percent agreement represented the percent of patients for whom the access was the same. Multivariate logistic analysis was performed to identify characteristics associated with the agreement of reported access.

Results: The two data sources agreed for $94 \%$ of patients, with a Kappa statistic of 0.83 , indicating an excellent level of agreement. Further, we found no evidence to suggest that agreement was associated with the patient characteristics of age, sex, race, or primary cause of renal failure.

Conclusion: These results suggest that vascular access data as reported on form CMS-2728 are valid and reliable for use in research studies.
\end{abstract}

Keywords: Hemodialysis, Medicare, Validation, Vascular access

\section{Background}

In hemodialysis patients, the choice of vascular access type is of primary importance. It is generally accepted that long-term use of catheters can cause vein stenosis [1,2], and catheters are associated with adverse outcomes such as infections and complications [3], compared with arteriovenous fistulas (AVFs) and arteriovenous grafts (AVGs). Additionally, rates of morbidity and mortality are lower for patients who use an internal access (AVF or AVG) [4-15], use of intravenous iron and/or erythropoietin is often lower [16-18], and health care-related costs

\footnotetext{
* Correspondence: csolid@usrds.org

'United States Renal Data System, Minneapolis Medical Research Foundation, 914 South 8th Street, Suite S4.100, Minneapolis, Minnesota 55404, USA Full list of author information is available at the end of the article
}

may be lower [19-22]. Clinical guidelines established by the National Kidney Foundation cite these reasons in advocating use of AVFs whenever possible [23]. The Fistula First campaign was developed to promote use of AVFs for dialysis patients $[24,25]$. Placement rates for each type of access have changed dramatically over the last 10 years [26], with a decrease in catheter placement rates and an increase in AVF placement rates.

In 2005, the Centers for Medicare \& Medicaid Services (CMS) revised the end-stage renal disease (ESRD) Medical Evidence Report (form CMS-2728) to collect information regarding the type of access used at the first outpatient dialysis session for incident patients. While some studies have used the vascular access data from form CMS-2728, lack of validation of those data is cited as a limitation by

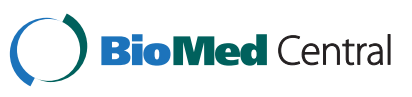


several authors [27-30]. Previous studies have attempted to validate other data from form CMS-2728, resulting in varying levels of validity and reliability [31-33].

Beginning in July 2010, outpatient dialysis facilities were required to report the type of vascular access used for dialysis on claims submitted to Medicare for payment. This represented the first time that vascular access was reported on Medicare claims, and provided an opportunity to compare the reported access on form CMS-2728 with the reported access on Medicare claims. The purpose of this study was to determine the agreement between the reported vascular access at initiation from these two data sources.

\section{Methods}

\section{Patients}

To ensure the presence of Medicare outpatient dialysis claims at hemodialysis initiation, only patients who were eligible for Medicare before ESRD onset were considered (for patients not Medicare eligible at initiation, Medicare eligibility does not begin until the fourth month of dialysis). Using the United States Renal Data System (USRDS) database, we identified patients aged 67 years or older at the time of initiation who began hemodialysis as their first mode of renal replacement therapy in July through December 2010, and who were Medicare eligible with Medicare as their primary payer. Patients with missing or invalid data from form CMS-2728 were excluded. Eligible patients were also required to have at least one valid Medicare outpatient dialysis claim within 14 days after their ESRD incidence date. Patient characteristics were obtained from the USRDS enrollment database.

\section{Vascular access}

The type of vascular access reported on form CMS-2728 was obtained from question 18d, "What access was used on first outpatient dialysis?" Dialysis claims were identified through the use of revenue center codes (0820 through 0829). To determine the vascular access reported on the first Medicare outpatient dialysis claim after hemodialysis initiation, Healthcare Common Procedure Coding System (HCPCS) modifier codes were used; the modifiers V5, V6, and V7 indicate catheter, AVG, and AVF, respectively.

\section{Analysis}

For each patient, the reported access from each data source was compiled, and the percent agreement represented the percent of patients for whom the access was the same (i.e., catheter, AVF, or AVG). The Kappa statistic was calculated as another measure of agreement [34,35]. Multivariate logistic analysis was performed to identify characteristics associated with the agreement of reported access. The dichotomous response variable was whether or not the reported access from the two data sources agreed (1) or disagreed (0).
Studies conducted under the auspices of the USRDS are exempt from institutional review board approval.

\section{Results}

Of the 13,662 incident hemodialysis patients aged 67 years or older with Medicare coverage at initiation, 211 had an invalid form CMS-2728 or unknown vascular access, and another 3674 lacked an outpatient dialysis claim within 14 days of initiation, resulting in a final study cohort of 9777 patients. The average age was 77.2 years with a range of 67 to 102 years (Table 1). About three-fourths of patients were white, and another $18 \%$ were African American. About $8 \%$ of patients identified as Hispanic. The most common primary causes of renal failure were diabetes (40\%) and hypertension (39\%).

The distribution of vascular access type identified by each data source and the number of instances of agreement and disagreement appear in Table 2. One patient for whom modifier codes indicated both a catheter and an AVG on the first outpatient dialysis claim was included in the catheter category. The two data sources produced very similar distributions of vascular access use (78\% catheter, $18 \%$ AVF, 4\% AVG), and the two sources agreed on the reported access type for $94 \%$ of patients, with a Kappa statistic of $0.83(P=0.0066,95 \%$ confidence interval 0.82-0.85).

Table 1 Patient characteristics $(n=9777)$

\begin{tabular}{lcc}
\hline Variable & $\boldsymbol{n}$ or mean (SD) & Percent \\
\hline Age, years & $77.2(6.6)$ & \\
Mean & 3770 & 38.6 \\
$67-74$ & 4478 & 45.8 \\
$75-84$ & 1529 & 15.6 \\
$\geq 85$ & & \\
Sex & 5213 & 53.3 \\
Male & 4563 & 46.7 \\
Female & & \\
Race & 7457 & 76.3 \\
White & 1784 & 18.2 \\
African American & 442 & 4.5 \\
Asian/Pacific Islander & 94 & 1.0 \\
Other & & \\
Ethnicity & 760 & 7.8 \\
Hispanic & 9017 & 92.2 \\
Non-Hispanic & & \\
Primary cause of ESRD & 3910 & 40.0 \\
Diabetes & 3772 & \\
Hypertension & 2095 & \\
Other/unknown & & \\
\hline ESD,End-stage rena disase & & \\
\hline
\end{tabular}

ESRD, End-stage renal disease; SD, Standard deviation. 
Table 2 Agreement of reported access

\begin{tabular}{|c|c|c|c|c|c|}
\hline & & \multicolumn{3}{|c|}{ Access reported on first outpatient dialysis claim } & \multirow[b]{2}{*}{ Total } \\
\hline & & Catheter & AVF & AVG & \\
\hline \multirow[t]{4}{*}{ Access reported on form CMS-2728 } & Catheter & 7406 & 189 & 63 & $7658(78.3)$ \\
\hline & AVF & 200 & 1490 & 58 & $1748(17.9)$ \\
\hline & AVG & 34 & 29 & 308 & $371(3.8)$ \\
\hline & Total & 7640 (78.1) & 1708 (17.5) & $429(4.4)$ & 9777 \\
\hline
\end{tabular}

Note: Values are $n$ or $n$ (\%).

$A V F$, Arteriovenous fistula; AVG, Arteriovenous graft; CMS, Centers for Medicare \& Medicaid Services.

Results of the multivariate logistic regression (Table 3) suggest that agreement was not associated with the patient characteristics of age, sex, race, Hispanic ethnicity, or primary cause of renal failure. In fact, the $P$ value for the global test for the model was non-significant (likelihood ratio $P=0.15$ ), indicating no evidence that any included variable was associated with the agreement in reported vascular access.

\section{Discussion}

This study represents the first time that vascular access data from form CMS-2728 have been compared with the access type reported on Medicare outpatient claims for the same patients. In general, we found excellent agreement between the two data sources; $94 \%$ of the time, the reported access was the same, and the Kappa value of 0.83 is above the threshold of 0.75 typically associated with an indication of excellent agreement [36]. Additionally, from multivariate logistic regression, instances of disagreement appeared to be independent of the patient characteristics of age, sex, race, and primary cause of renal failure. This is encouraging, because it suggests that the validity is likely to be equally strong across different patient populations. Disagreement was more common when an AVF or AVG was reported than when a catheter was reported. However, the use and reporting of catheters far out-number the use and

Table 3 Multivariate logistic regression on the agreement of vascular access

\begin{tabular}{lcc}
\hline Variable & Estimated odds ratio & $\boldsymbol{P}$ \\
\hline Male sex & Reference & \\
Female sex & 0.97 & 0.7296 \\
Age 67-74 years & Reference & \\
Age 75-84 years & 0.92 & 0.3720 \\
Age $\geq 85$ years & 1.09 & 0.5321 \\
White race & Reference & \\
African American race & 0.81 & 0.0520 \\
Other race & 0.80 & 0.2183 \\
Non-Hispanic ethnicity & Reference & 0.2067 \\
Hispanic ethnicity & 1.26 & \\
\hline
\end{tabular}

reporting of AVFs or of AVGs, and the distribution of access type reported is in line with the overall distribution. For example, for the 258 cases in which outpatient claims did not agree with AVF access reported on form CMS-2728, 78\% of the time the outpatient claims indicated catheter use, which is exactly the percentage of catheters reported overall, and what would be expected if disagreement were random.

The limitations of this study should be noted. The study population was limited to patients aged 67 years or older, and the distribution of the access type used (and reported) may not be representative of the entire incident hemodialysis population. However, the analysis of this population suggested that the validity was not associated with age, and while the results are not generalizable to the population aged younger than 67 years, there is nothing to indicate that validity would differ significantly in a younger population. Another limitation is that form CMS-2728 may be filled out weeks or months after dialysis initiation, with unknown consequences for the reliability of the information on the form. However, for patients in this study, the date of the physician's signature on the form occurred, on average, 20.4 days after the date that regular dialysis began, and did not differ significantly $(P=$ $0.36)$ for patients with access type agreement (20.5 days) vs. those with lack of agreement (19.6 days) on the first outpatient dialysis Medicare claim. Also, dialysis providers are required to report only the vascular access used for the last hemodialysis session of the month, and reporting the access at each session is at the provider's discretion. Therefore, in some cases, the access reported on the dialysis claim may not reflect the access used for the first outpatient dialysis session. (In fact, agreement when form CMS-2728 indicates a catheter is slightly worse when the form also indicates presence of a maturing AVF or AVG, possibly reflecting instances of a catheter being used at the first session and an AVF or AVG having matured by the end of the month and thus appearing on the outpatient claim). However, this situation would only serve to increase the difficulty of concordance with form CMS2728, making our findings all the more encouraging. For researchers hoping to resolve cases in which the data sources disagree, searching for claims involving 
access procedures (insertions, removals, complications) may provide additional information regarding the type or types of access present at initiation. Finally, this study simply investigated concordance between two data sources, not concordance with type of vascular access actually present, which is ultimately unknown. Future study is warranted, perhaps involving primary data collection regarding the true vascular access used at each dialysis session, to compare with access reported on claims and on form CMS-2728.

\section{Conclusions}

The degree of agreement between form CMS-2728 and outpatient dialysis claims reporting of the type of vascular access used at hemodialysis initiation should give researchers confidence in using data from either source in future studies.

\section{Abbreviations}

AVF: Arteriovenous fistula; AVG: Arteriovenous graft; CMS: Centers for Medicare \& Medicaid Services; ESRD: End-stage renal disease; USRDS: United States Renal Data System.

\section{Competing interests}

This study was performed as a deliverable under Contract No. HHSN267200715002C (National Institute of Diabetes and Digestive and Kidney Diseases, National Institutes of Health, Bethesda, Maryland). The authors report no competing interest with this study's subject matter.

\section{Authors' contributions}

$\mathrm{CS}, \mathrm{AC}, \mathrm{JE}, \mathrm{SC}, \mathrm{AF}, \mathrm{RF}$, and Al made substantial contributions to conception and design of the study. JE and SC contributed to acquisition of data. CS, JE, $\mathrm{SC}, \mathrm{RF}$, and $\mathrm{Al}$ analyzed and interpreted the data. CS, AC, JE, SC, AF, RF, and Al drafted the article or revised it critically for important intellectual content. CS, AC, JE, SC, AF, RF, and Al gave final approval of the version to be published. All authors read and approved the final manuscript.

\section{Acknowledgments}

The authors thank United States Renal System colleagues Beth Forrest for regulatory assistance, Delaney Berrini, BS, for manuscript preparation, and Nan Booth, MSW, MPH, ELS, for manuscript editing.

\section{Author details}

'United States Renal Data System, Minneapolis Medical Research Foundation, 914 South 8th Street, Suite S4.100, Minneapolis, Minnesota 55404, USA. ${ }^{2}$ Department of Medicine, University of Minnesota, Minneapolis, Minnesota, USA. ${ }^{3}$ Division of Renal Diseases and Hypertension, University of Minnesota, Minneapolis, Minnesota, USA. ${ }^{4}$ Section of Nephrology, Minneapolis VA Health Care System, Minneapolis, Minnesota, USA.

Received: 23 May 2013 Accepted: 2 February 2014

Published: 8 February 2014

\section{References}

1. Barrett N, Spencer S, Mclvor J, Brown EA: Subclavian stenosis: a major complication of subclavian dialysis catheters. Nephrol Dial Transplant 1988, 3:423-425.

2. Spinowitz BS, Galler M, Golden RA, Rascoff JH, Schechter L, Held B, Charytan C: Subclavian vein stenosis as a complication of subclavian catheterization for hemodialysis. Arch Intern Med 1987, 147:305-307.

3. National Kidney Foundation: An introduction to the kidneys and chronic kidney disease. Available at: www.kidney.org. 2011. Accessed January 22, 2014.

4. Astor BC, Eustace JA, Powe NR, Klag MJ, Fink NE, Coresh J: Type of vascular access and survival among incident hemodialysis patients: the choices for healthy outcomes in caring for ESRD (CHOICE) study. J Am SOC Nephrol 2005, 16:1449-1455.
5. Dhingra RK, Young EW, Hulbert-Shearon TE, Leavey SF, Port FK: Type of vascular access and mortality in U.S. hemodialysis patients. Kidney Int 2001, 60:1443-1451.

6. Feldman HI, Held PJ, Hutchinson JT, Stoiber E, Hartigan MF, Berlin JA: Hemodialysis vascular access morbidity in the United States. Kidney Int 1993, 43:1091-1096

7. Gulati S, Sahu KM, Avula S, Sharma RK, Ayyagiri A, Pandey CM: Role of vascular access as a risk factor for infections in hemodialysis. Ren Fail 2003, 25:967-973.

8. Ishani A, Collins AJ, Herzog CA, Foley RN: Septicemia, access and cardiovascular disease in dialysis patients: the USRDS Wave 2 study. Kidney Int 2005, 68:311-318.

9. Nassar GM, Ayus JC: Infectious complications of the hemodialysis access. Kidney Int 2001, 60:1-13.

10. Perera GB, Mueller MP, Kubaska SM, Wilson SE, Lawrence PF, Fujitani RM: Superiority of autogenous arteriovenous hemodialysis access: maintenance of function with fewer secondary interventions. Ann Vasc Surg 2001, 18:66-73.

11. Polkinghorne KR, McDonald SP, Atkins RC, Kerr PG: Vascular access and all-cause mortality: a propensity score analysis. J Am Soc Nephrol 2004, 15:477-486.

12. Raithatha A, McKane W, Kendray D, Evans C: Catheter access for hemodialysis defines higher mortality in late-presenting dialysis patients. Ren Fail 2010, 32:1183-1188.

13. Schlieper G, Kruger T, Djuric Z, Damjanovic T, Markovic N, Schurgers $L$, Brandenburg VM, Westenfeld R, Dimkovic S, Ketteler M, Grootendorst DC Dekker FW, Floege J, Dimkovic N: Vascular access calcification predicts mortality in hemodialysis patients. Kidney Int 2008, 74:1582-1587.

14. Woods JD, Port FK: The impact of vascular access for haemodialysis on patient morbidity and mortality. Nephrol Dial Transplant 1997, 12:657-659.

15. Xue JL, Dahl D, Ebben JP, Collins AJ: The association of initial hemodialysis access type with mortality outcomes in elderly Medicare ESRD patients. Am J Kidney Dis 2003, 42:1013-1019.

16. Chand DH, Teo BW, Fatica RA, Brier M: Influence of vascular access type on outcome measures in patients on maintenance hemodialysis. Nephron Clin Pract 2008, 108:c91-c98.

17. Goicoechea M, Caramelo C, Rodriguez P, Verde E, Gruss E, Albalate M, Ortiz A, Casado S, Valderrábano F: Role of type of vascular access in erythropoietin and intravenous iron requirements in haemodialysis. Nephrol Dial Transplant 2001, 16:2188-2193.

18. Lopez-Gomez JM, Portoles JM, Aljama P: Factors that condition the response to erythropoietin in patients on hemodialysis and their relation to mortality. Kidney Int 2008, 74(Suppl 111):S75-S81.

19. United States Renal Data System: The cost effectiveness of alternative types of vascular access and the economic cost of ESRD. Bethesda, MD: National Institutes of Health, National Institute of Diabetes and Digestive and Kidney Disorders; 1995:139-157.

20. Schon D, Blume SW, Niebauer K, Hollenbeak CS, de LG: Increasing the use of arteriovenous fistula in hemodialysis: economic benefits and economic barriers. Clin J Am Soc Nephrol 2007, 2:268-276.

21. Solid CA, Carlin C: Timing of arteriovenous fistula placement and Medicare costs during dialysis initiation. Am J Nephrol 2012, 35:498-508.

22. Wu LC, Lin MY, Hsieh CC, Chiu HC, Mau LW, Chiu YW, Chen HC, Hwang SJ: Planned creation of vascular access saves medical expenses for incident dialysis patients. Kaohsiung J Med Sci 2009, 25:521-529.

23. National Kidney Foundation. NKF KJDOQI Guidelines: Clinical practice guidelines and clinical practice recommendations, 2006 updates hemodialysis adequacy, peritoneal dialysis adequacy, vascular access. Available at: http://www.kidney.org/professionals/Kdoqi/guideline_upHD_PD_VA/ va_guide1.htm. Accessed January 22, 2014.

24. Lok CE: Fistula first initiative: advantages and pitfalls. Clin J Am Soc Nephrol 2007, 2:1043-1053.

25. Lacson E Jr, Lazarus JM, Himmelfarb J, Ikizler TA, Hakim RM: Balancing fistula first with catheters last. Am J Kidney Dis 2007, 50:379-395.

26. US Renal Data System: USRDS 2010 Annual Data Report: Atlas of Chronic Kidney Disease \& End-Stage Renal Disease in the United States, Volume 2. Figure HP.13., 2010 ed. Bethesda, MD: National Institutes of Health, National Institute of Diabetes and Digestive and Kidney Diseases; 2010:217.

27. Arce CM, Mitani AA, Goldstein BA, Winkelmayer WC: Hispanic ethnicity and vascular access use in patients initiating hemodialysis in the United States. Clin J Am Soc Nephrol 2012, 7:289-296. 
28. Foley RN, Chen S, Collins A: Hemodialysis access at initiation in the US, 2005-2007: still "catheter first". Hemodial Int 2009, 13:533-542.

29. Lilly MP, Lynch JR, Wish JB, Huff ED, Chen SC, Armistead NC, McClellan WM: Prevalence of arteriovenous fistulas in incident hemodialysis patients: correlation with patient factors that may be associated with maturation failure. Am J Kidney Dis 2012, 59:541-549.

30. McClellan WM, Wasse H, McClellan AC, Holt J, Krisher J, Waller LA: Geographic concentration of poverty and arteriovenous fistula use among ESRD patients. J Am Soc Nephrol 2010, 21:1776-1782.

31. Beaubrun AC, Kanda E, Bond TC, McClellan WM: Form CMS-2728 data versus erythropoietin claims data: implications for quality of care studies. Ren Fail 2013, 35:320-326.

32. Kim JP, Desai M, Chertow GM, Winkelmayer WC: Validation of reported predialysis nephrology care of older patients initiating dialysis. J Am SoC Nephrol 2012, 23:1078-1085.

33. Merkin SS, Cavanaugh K, Longenecker JC, Fink NE, Levey AS, Powe NR Agreement of self-reported comorbid conditions with medical and physician reports varied by disease among end-stage renal disease patients. $J$ Clin Epidemiol 2007, 60:634-642.

34. Cohen J: A coefficient of agreement for nominal scales. Educ Psychol Meas 1960, 20:37-46.

35. Fleiss $\mathrm{U}$, , Cohen J: Large sample standard errors of kappa and weighted kappa. Psychological Bull 1969, 72:323-327.

36. Landis J, Koch G: The measurement of observer agreement for categorical data. Biogeosciences 1977, 33:159-174.

doi:10.1186/1471-2369-15-30

Cite this article as: Solid et al:: Agreement of reported vascular access on the medical evidence report and on medicare claims at hemodialysis initiation. BMC Nephrology 2014 15:30.

\section{Submit your next manuscript to BioMed Central and take full advantage of:}

- Convenient online submission

- Thorough peer review

- No space constraints or color figure charges

- Immediate publication on acceptance

- Inclusion in PubMed, CAS, Scopus and Google Scholar

- Research which is freely available for redistribution 